\title{
HEROÍNAS ANTE EL ESPEJO. REFLEJOS DE EURÍDICE Y PERSÉFONE EN LA TRANSFORMACIÓN PERSONAL DE GINEVRA WEASLEY
}

\author{
Irene del Carmen Marcos Arteaga
}

\section{RESUMEN}

Este artículo pretende trabajar la habilidad de J.K. Rowling en el uso de la mitología grecorromana, especialmente a la hora de adaptarla y transformarla en la redacción de algunos de los relatos de sus novelas. En este caso trabajaremos sobre los episodios de Perséfone y Eurídice utilizados en el descenso al «Hades» de Ginny Weasley en Harry Potter y la Cámara de los Secretos. Pero no sólo nos interesa conceptualizar los cambios y variantes de la visión creativa de la autora, sino cómo éstos se ven afectados a la hora de traspasar la gran pantalla, analizando para ello el resto de referentes artísticos propuestos para la puesta en escena. En definitiva, nos gustaría demostrar cuánto hay de deconstrucción de los mitos antiguos y cuánto de creación de nuevas lecturas e imágenes a partir de ellos en el segundo filme de la famosa saga.

Palabras clave: Harry Potter, mito, Perséfone, Eurídice.

\section{HEROINES THROUGH THE LOOKING-GLASS. EURYDICE AND PERSEPHONE IN GINEVRA WEASLEY'S PERSONAL TRANSFORMATION}

\section{Abstract}

Our paper aims to highlight the ability of J.K.Rowling using Greek and Roman mythology, especially to adapt it and transform it into her stories. In this particular case we are talking about Persephone and Eurydice episodes, which have been used in the descent to Hades by Ginny Weasley in the summit scene of Harry Potter and the Chamber of Secrets. We are interested in conceptualizing changes and variations of the creative vision of the author, and how those have been affected when they moved to the big screen, analyzing the rest of artistic references that were selected for staging. Ultimately, we would like to prove how she deconstructs the ancient myths and how she creates new readings and new images based on them in the second film of the famous saga.

Keywords: Harry Potter, myth, Persephone, Eurydice. 
Desde el Kolossal al péplum, y desde éste hasta la actualidad, la presencia de la mitología en el cine ha sido permanente aunque no constante.

La renovación y el éxito del "género" -llamémoslo así- ha permitido que obras de espíritu muy diferente muestren adaptaciones de episodios destacados de la mitología grecorromana en películas de índole diversa, aunque especialmente pertenecientes al fantástico. Pensemos, en este sentido, en Percy Jackson y el ladrón del rayo (Percy Jackson and the Olympians: The Lightning Thief, Chris Columbus 2010), o en la que trataremos en el presente trabajo, Harry Potter, la saga de la británica J.K. Rowling, referente juvenil por excelencia.

Es cierto, que estas últimas no sólo bucean entre las páginas de los antiguos, sino que en sus imágenes podemos encontrar innumerables referencias a las mitologías nórdica, cristiana, a las sagas artúricas e incluso a las tradiciones populares británicas. Por todo ello, el presente trabajo intentará demostrar cómo y de qué manera la autora de la saga bebe de fuentes clásicas a la hora de desarrollar determinados contenidos de su obra, tanto a nivel del tratamiento de alguno de sus personajes como de la propia diégesis del relato, aunque creando y obedeciendo sus propias reglas, que, obviamente, altera y modifica en relación con el discurso que propone en cada una de las novelas, lo que claramente se subraya cuando éstas han ido pasando a la gran pantalla.

Estas referencias llegan incluso a la selección de los nombres que escoge para sus protagonistas. Estamos, por tanto, ante una escritora que no «inventa» nada per se, pero que es capaz de cubrirlo por múltiples capas de literatura fantástica que hacen que el lector se sumerja en la historia sin percibir con claridad -en caso de que la conozca- de dónde viene su inspiración y cuáles son los referentes que altera y adapta para que parezcan nacidos directamente de su pluma.

Para ello, nos vamos a centrar en cómo utiliza dos episodios míticos diferentes, los de Perséfone y Eurídice, como referencia obvia en la escena del descenso al «Hades» de Ginny Weasley -en realidad, a la denominada «Cámara de los Secretos»- en la segunda novela y película de la saga, de título homónimo, Harry Potter and the Chamber of Secrets, publicada en 1998 y exhibida en los cines en 2002 bajo la dirección de Chris Colombus, siendo producida por la británica Heyday Films y distribuida por la Warner Bros.

\section{RELACIONES MITO-CINE-FANTASÍA: ALGUNAS CLAVES}

Como bien sabemos, la mitología clásica surgió para dar sentido y para explicar la concepción del mundo y de la naturaleza a los antiguos griegos; así como para ahondar en la psiquis del ser humano y, por ende, entender la dicotomía entre el universo racional y su imagen especular.

Son relatos que tienden a explicar la legitimidad del presente de un pueblo a través de dioses, héroes y seres sobrenaturales. En el caso de los griegos, no sería hasta la llegada de la escritura cuando el relato mítico se convirtiese en un elemento de cohesión cultural y religiosa en una Grecia políticamente muy fragmentada (Pérez, 2013: 34). Naturalmente, las artes plásticas contribuyeron al proceso de 
antropomorfización en las representaciones de unos personajes que han creado fascinación hasta nuestros días. Desde un primer momento los mitos han abastecido el imaginario popular, eso sí, cambiando su significado primigenio con el paso del tiempo para convertirse en historias que ilustraban un pasado remoto, transformándose en epítomes de éste, primero gracias a la literatura y, desde el siglo pasado, al cine y más tarde a la televisión, estando así mucho más presentes en nuestra sociedad y siendo conocidas por las generaciones más jóvenes.

Quizás por ello a Georges Méliés le interesara aproximarse al mundo grecorromano, con obras como Pigmalión y Galatea (Pygmalion et Galathée 1898); sin embargo, los primeros éxitos del cine italiano decantaron las referencias más frecuentes a episodios históricos y no tanto a los mitológicos, siendo así como surgieron en las primeras décadas del siglo pasado obras como Nerón o La caída de Roma (Nero, or the fall of Rome 1909), Los últimos días de Pompeya (Gli ultimi giorni di Pompeii 1908) de Luigi Maggi y La caída de Troya (La caduta di Troia 1910) de Giovanni Pastrone.

Si bien los años 60 fueron la década gloriosa del péplum, es cierto que desde los 30 no dejaron de producirse películas de este subgénero histórico. No obstante, de los 80 en adelante, con Furia de Titanes (Clash of the Titans, Desmond Davis 1981) o Hércules (Hercules, John Musker y Ron Clements 1997) de Disney, se ha vuelto a vivir una nueva edad de oro.

En el caso que nos ocupa daremos un salto en el tiempo, ya que nuestro trabajo se centra en producciones de principios del siglo actual. Así pues, desde su comienzo y coincidiendo con la realización de las primeras películas de Rowling, se produce una revitalización del género. Con Ridley Scott y su Gladiator, entramos en el péplum contemporáneo gracias a una sólida historia de intriga, de amor, pero también de odio, orgullo y nobleza; todo ello combinado con unos efectos especiales hasta entonces nunca vistos. El año 2004 será clave debido al estreno de Troya (Troy, Wolfgang Petersen), La pasion de Cristo (The Passion of the Christ, Mel Gibson), Alejandro Magno (Alexander, Oliver Stone) y El rey Arturo (King Arthur, Antoine Fuqua); puesto que con ellas cambiaría definitivamente la visión que el cine había dado de la Antigüedad, ya que las nuevas tecnologías permitieron la recreación de espacios del pasado, mítico o no, sin parangón en décadas anteriores.

Algo más tarde comenzarían a desarrollarse producciones británicas como Centurión (Centurion, Neil Marshall 2010) o La legión del águila (The Eagle, Kevin McDonald 2011), centradas en la presencia romana en la antigua Britania y que abordaban aspectos totalmente desconocidos hasta el momento por este cine, como la aculturación o los problemas lingüísticos. Como bien dice David Serrano Lozano (2012), «se trata de una visión más compleja del mundo antiguo que trasluce una cierta influencia del mundo académico en la producción cinematográfica, con relatos de carácter bélico replanteados desde una óptica que ahonda en las complejidades entre bandos, el contexto cultural del momento, etc.».

El resurgir de estas historias épicas sobre la Antigüedad, con base real o mitológica, viene muy estrechamente ligado al boom editorial de la novela fantástica/maravillosa, tanto de autores clásicos como actuales, y de las sagas surgidas a partir de ellas. Nos referimos no obviamente al género en sí, sino a que muchos de 
los nuevos personajes que aparecen en ellas tiñen su idiosincrasia de valores heroicos propios de los mitos grecorromanos. Es así que en obras donde predomina lo sobrenatural sus protagonistas se construyen a partir los citados referentes clásicos -o bien de otras mitologías cercanas al mundo anglosajón-.

Uno de sus máximos exponentes y precursores fue J.R.R. Tolkien, colega de C.S. Lewis e inspirador de tantos escritores con posterioridad, especialmente de J.K. Rowling. Si analizamos las obras de los tres citados podremos observar que combinan un sinfín de referencias, no sólo del mundo grecorromano, sino también de la mitología nórdica o de las sagas artúricas. Toda esta mezcla de tradiciones ha quedado definida por Héctor Pérez (2013: 86-90) como una técnica narrativa basada en el pastiche, en donde sus autores juegan con diferentes mundos mitológicos para conformar un universo propio e identificable por el público y con un gran éxito comercial, tanto para los editores como para las productoras, que apuestan por la adaptación de las mismas en la gran pantalla.

Si observamos con detenimiento El señor de los Anillos, Las crónicas de Narnia o Harry Potter, podemos establecer, en términos generales, una serie de características que, bien definidas y recogidas por el citado autor, serían las siguientes:

... en estas narraciones hay siempre monstruos y seres heroicos de poderes extraordinarios que luchan contra ellos (venciendo finalmente siempre), brujas y/o duendes, encantamientos, paisajes que nunca veremos con nuestros propios ojos y un recurrente enfrentamiento generalizado entre las fuerzas del bien y del mal. La tradición de la que hablamos coincide con el género fantástico y no acaba con las doradas sagas de El señor de los anillos (J.R.R. Tolkien, 1954) y Harry Potter (J.K. Rowling, 1997) sino que sigue aún hoy tremendamente viva, como lo prueban la entidad y frecuencia de las últimas producciones del siglo xxi: Las crónicas de Narnia (Andrew Adamson, 2005), La brújula dorada (Chris Weitz, 2007) o Beowulf (Zemeckis, 2007) (2013: 23).

\section{J.K. ROWLING Y EL USO DE LA MITOLOGÍA GRECORROMANA}

A principios de los años 80, Joanne Rowling se graduó en Filología Francesa y Clásica en la Universidad de Exeter. Fue durante esos ańos cuando se enamoró de la literatura clásica, por lo que decidió estudiar la tragedia griega, los cuentos homéricos y la mitología del Mundo Antiguo. Así pues, no es de extrañar que, sin adentrarnos en profundidad en la saga de Harry Potter, encontremos cuantiosas referencias al mundo clásico.

Sin embargo, la tradición grecorromana no es la única que inspira sus historias. A lo largo de las siete novelas aparecen también veladas alusiones a las sagas artúricas, a episodios bíblicos y a la mitología nórdica. Obviamente, J.K. Rowling no copia estos asuntos, sino que los reinterpreta y transforma. Esto se traduce en la reproducción de las estructuras narrativas pero sin la linealidad de las mismas; por ejemplo, cuando Harry se adentra en la Cámara de los Secretos en busca de Ginny éste se nos presenta como un Orfeo moderno pero a la vez como un Heracles que tiene que ir sorteando, novela a novela, película a película, las pruebas a las que le somete 
su mortal enemigo, lord Voldemort. Esta mezcla de episodios míticos es constante a lo largo de toda la saga, no siendo un fenómeno aislado o único. En otros casos, la semejanza o similitud deriva de la función de determinados objetos, como sería el uso del colmillo del basilisco para la destrucción de uno de los horrocruxes, que nos recuerda al que se hace de la cabeza de la Gorgona, cuando Perseo se la entrega a Atenea y ésta la coloca en su escudo -la égida- para protegerse de sus enemigos.

Como hemos apuntado, la tradición griega no es la única que nutre sus historias, pero sí la que más estudios académicos ha generado desde las diferentes disciplinas de las humanidades, caso de la filología o la filosofía.

\subsection{El uso de los mitos de Perséfone y Eurídice en la literatura de J.K. RowLING}

Tanto cuando leemos como cuando vemos la película Harry Potter y la Cámara de los Secretos nos damos cuenta de que estamos asistiendo al uso y a una nueva adaptación de dos episodios míticos griegos, las historias de Perséfone y Eurídice. Rowling consigue fundir en el personaje de la joven Weasley el espíritu de esas dos mujeres que protagonizaron importantes sucesos en el cosmos del Señor del Inframundo, Hades; por ello no es de extrańar que compartan la misma estructura narrativa. Claramente podemos dividir sus historias en cuatro momentos clave: el rapto, la búsqueda de las jóvenes, el regreso y la plasmación de la vuelta a la normalidad.

En el caso de la primera de ellas se nos indica que Perséfone fue raptada de manera violenta por Hades y tan sólo Hécate y Sol consiguieron oír los gritos de la joven. Eurídice, sin embargo, está bailando con las náyades cuando de repente fue mordida por una cobra en el talón. Es entonces cuando ésta desciende al Hades. En el caso de Ginny Weasley, no se produjo un rapto violento, sino que sería hechizada en Hogwarts a través del diario de Tom Riddle y llevada, involuntariamente, eso sí, a la Cámara de los Secretos.

Tanto con Eurídice como con Ginny, son sus parejas quienes comienzan una ardua búsqueda para encontrarlas. En el primer caso, Orfeo la llora desconsoladamente hasta que decide bajar al Hades para negociar con sus reyes la salida de la misma. En el segundo, Harry y Ron encuentran una pista que su amiga Hermione les deja y que hallan en la mano de ésta mientras estaba en la enfermería, ya que había sido petrificada por la bestia que moraba en el castillo. Sin embargo, con Perséfone, es su madre la que decide emprender un viaje para dar con su hija. Sería entonces cuando se reuniría con Hécate y con Sol, siendo finalmente éste quien le desvela que ha sido Hades, en connivencia con Zeus, quien se ha llevado a su amada hija.

Pero donde quizás encontremos más paralelismos sea en el momento en que se produce la esperada vuelta de las jóvenes. Sabemos que Zeus tiene que mediar ante la furia de Deméter y para ello el dios de dioses del Olimpo dictamina que si Perséfone no ha probado ningún alimento del Hades, podría regresar junto a su madre en la tierra. El problema resulta cuando, poco antes de salir, Hades le ofrece una granada a la joven y ésta se la come. Esto supuso un regreso "estacionario» en donde la mitad del año estaría con su madre (asistimos entonces al renacer de la 
vegetación) y la otra mitad sería la reina del Hades. Por su parte, Orfeo suplica a los reyes del Inframundo que le devuelvan a su esposa. Se dice que Perséfone, conmovida por las palabras y la música de Orfeo, decide dejarla salir con una condición: que no volviese la vista atrás hasta que hubiesen salido. Sin embargo, las ansias del joven hacen que se gire a ver si ésta estaba provocando que se perdiese nuevamente en el Hades. Finalmente, en el caso de Harry, éste consigue abrir la Cámara y allí se encuentra, no sólo con Ginny, sino también con Tom Riddle, que no es otro que lord Voldemort. Es entonces cuando se produce una conversación entre ambos que desemboca, finalmente, en la lucha del joven mago contra el basilisco. Tras derrotarle, Voldemort desaparece y Ginny despierta del «sueño» y junto a Harry sale de la Cámara de los Secretos gracias a Fawkes, el fénix de Dumbledore.

Como hemos podido observar, varios son los motivos y mitemas que muestran el paralelismo entre estas tres historias; compartir una misma estructura narrativa con variaciones introducidas por la escritora en beneficio de la misma, siendo una estrategia diegética que enriquece el relato.

\subsection{REFERENTES ICONOGRÁFICOS EN LA PLÁSTICA CONTEMPORÁNEA}

Los mitos de Perséfone y Eurídice han sido reinterpretados a lo largo del tiempo, resultando especialmente atractivos para los artistas y escritores románticos y finiseculares.

El arte del siglo xIx trajo un cambio sustancial para la iconografía clásica. Así, por ejemplo, el Neoclasicismo supuso una renovación en la forma de tratarla ya que este movimiento artístico retomó episodios históricos y mitológicos "para exaltar el heroísmo personal, el sacrificio de la propia vida en aras de mantener la propia conciencia, o al servicio de grandes ideales» (Carmona Muela, 2008: 14). La llegada del Romanticismo fue un punto de inflexión para la representación de los episodios míticos. Frente a los cánones y el constreñimiento de las academias, los pintores románticos encontraron en la luz y el color el vehículo perfecto para expresar sus pasiones más íntimas, al igual que hicieron los pintores simbolistas. Es por ello por lo que resulta interesante observar los recursos que emplearon para hacer creíbles, e incluso tangibles, los ambientes y personajes mitológicos, devolviéndoles una existencia inquietante y cargada de misterio; destacando el trabajo de los herederos del Prerrafaelismo. Ejemplos de ello fueron Gustave Moreau (Júpiter y Sémele, 1896), Jean Delville (La muerte de Orfeo, 1898) o Franz von Stuck (Circe ofreciendo su copa a Ulises, 1913).

Es aquí en donde la figura y la historia de Perséfone cobran mayor protagonismo. Como bien dice Popa-Liseanu, «éste adquiere gran importancia a finales del siglo xIX y principios del xx, pues los autores finiseculares, sobre todo ingleses, han visto en el mito de Proserpina un avatar del alma romántica misma» (2010: 205).

Hasta la llegada de Gustave Moreau y los prerrafaelistas, las representaciones de la hija de Deméter se caracterizaron por mostrárnosla como una víctima, una joven muchacha que había sido raptada violentamente y engañada por el Señor del Inframundo para que se quedase con él. Sin embargo, a finales del siglo XIx nos 


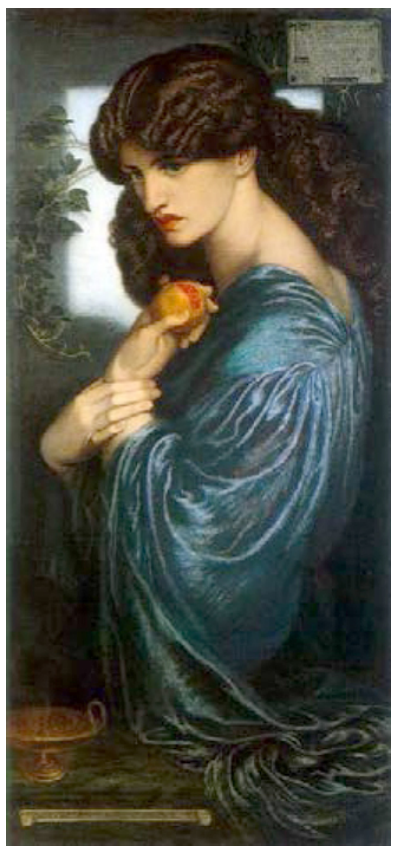

Dante Gabriel Rossetti, Proserpina.

encontramos con una mujer fuerte cuya carga psicológica y simbólica sentará las bases, junto con Pandora o Medea, de lo que conocemos como «mujer fatal». Ejemplo de ello podríamos verlo en la obra de Dante Gabriel Rossetti Perséfone (1874).

El artista británico pinta a Perséfone como reina del Inframundo en un espacio oscuro. En la obra sólo aparecen iluminados el pálido rostro y las manos de la joven. En una de ellas sostiene la granada que la ha condenado para siempre en el Hades, rodeada de un halo de misterio.

Al igual que sucede con Perséfone, la historia de los recién casados Orfeo y Eurídice adquiere matices trágicos e incluso oscuros con los trabajos de los artistas de finales del siglo XIX, como Camille Corot, Edward Burne-Jones o Frederic Leighton.

Éstos se centraron en la muerte de ambos amantes mientras que en otros periodos artísticos se prefirió la representación del Hades o el encuentro entre Orfeo y los reyes del Inframundo. En lo que respecta a la muerte de Eurídice la composición predominante es aquélla en la que la joven yace muerta entre los brazos de su marido, en medio de un espacio donde se prefieren los tonos fríos y la sombra, reservándose el foco de luz para el cuerpo inerte de la joven.

Si en Perséfone veíamos un cambio sustancial en cuanto a la concepción de la misma, de víctima pasa a ser verdugo, con Eurídice esto no sucede. Se nos sigue presentando como un personaje pasivo, una pobre víctima, no sólo por la tragedia que la rodea, sino también por la imprudencia y las ansias de Orfeo. 


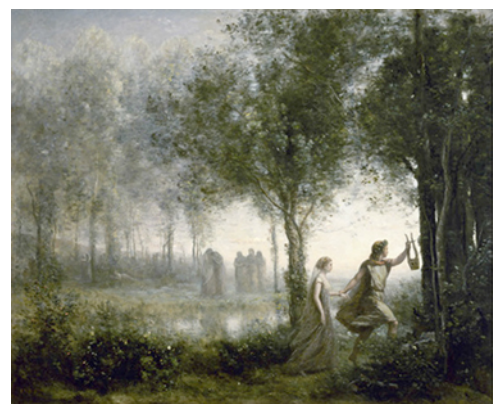

Camille Corot, Orfeo y Eurídice (1861).

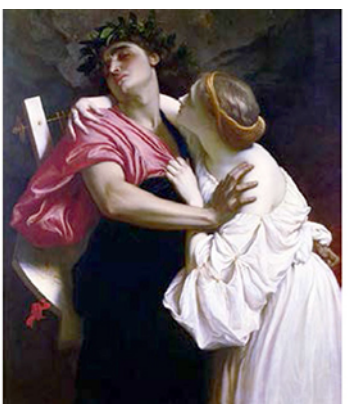

Frederic Leighton, Orfeo y Eurídice (1864).

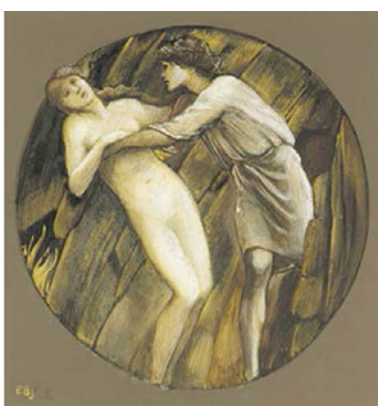

Edward Burne-Jones, Orfeo y Eurídice (1870).

Teniendo en cuenta todo esto, ¿¿de qué manera Chris Columbus y su equipo artístico emplearon todos estos referentes para la construcción de una de las escenas más importantes de la saga? Como veremos más adelante, son innegables las referencias literarias y plásticas para la realización de la misma; pero centrémonos un momento en la puesta en escena, pues, obviamente, Columbus juega con una fotografía oscura, en tonos muy fríos, situándonos en un lugar lúgubre, casi inhabitable, retratado con una gran profundidad de campo. La luz, al igual que sucede en los lienzos en los que aparece Eurídice, recae sobre Ginny Weasley, quien destaca en la composición por su pelo rojo y su pálida tez, único punto lumínico de la misma.

\section{GINEVRA Y SU RESCATE DEL HADES}

Tenía la cara tan blanca y fría como el mármol, aunque los ojos estaban cerrados, así que no estaba petrificada.

(J.K. Rowling)

Si leemos el Himno homérico a Deméter y el Libro X de Las Metamorfosis de Ovidio y los cotejamos con el relato de la escritora británica, nos damos cuenta de que, no sólo hay semejanzas, sino también diferencias en la construcción del episodio que protagoniza la hija más pequeña de Molly y Arthur Weasley en la Cámara de los Secretos.

En su primer año en Hogwarts, que corresponde al segundo que cursan los tres protagonistas de la saga: Harry Potter, Ron Weasley y Hermione Granger, sería embrujada por lord Voldemort a través del diario de Tom Riddle, obligándola a causar estragos en la escuela, poniendo en peligro la vida de otros estudiantes y forzándola a abrir la Cámara de los Secretos, habitación oculta construida por el fundador de la Casa Slytherin con la intención de que su habitante terminase su «noble tarea», acabar con los «sangre sucia» de Hogwarts. 


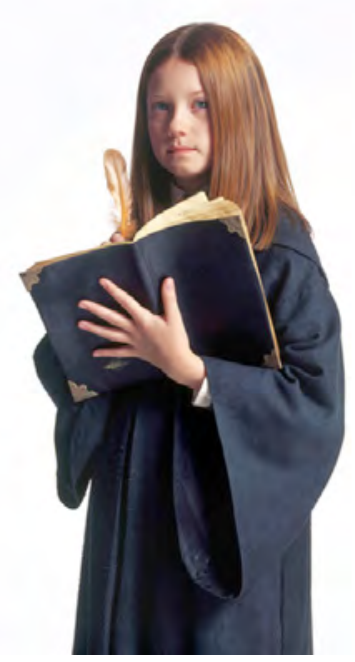

Ginny Weasley con el diario de Tom Riddle.

La finalidad de la posesión de Ginny por parte del Señor Tenebroso no era otra que matarla para así poder obtener más fuerza vital y poder materializarse.

Tras notar su ausencia, Harry decidirá emprender un camino, junto con su inseparable amigo Ron, a la Cámara en busca de la joven. Será entonces cuando asistamos a su descenso a un mundo subterráneo para enfrentarse «al mago más poderoso de todos los tiempos» y derrotar, con la espada de Godric Griffindor, al basilisco que habitaba en dicha cámara, que ya había petrificado con anterioridad a varios estudiantes de Hogwarts.

Estamos ante una historia aparentemente sencilla, destinada a un público juvenil, pero que encierra entre sus páginas múltiples referencias cruzadas, como acabamos de indicar.

R.A. Spencer (2015: 88), profesor universitario en Carolina del Norte, establece algunas semejanzas entre Perséfone y Ginevra, caso del rapto de las jóvenes por dos hombres poderosos que las llevan a un mundo subterráneo en contra de su voluntad, aunque mientras una es arrebatada del mundo de los vivos con violencia, la otra será hechizada para satisfacer los deseos de lord Voldemort. En este caso, el rapto de Ginny sólo era una excusa para encontrarse nuevamente con Harry y batirse otra vez con él, una vez que se hubiese materializado.

${ }^{1}$ Recordemos que los enfrentamientos entre lord Voldemort y Harry Potter se suceden a lo largo de las siete novelas escritas por J.K. Rowling hasta la gran batalla final. 
Spencer (2015) relaciona los caracteres de las mujeres, pues nos las presenta como jóvenes inocentes que han sido forzadas a realizar cosas que ninguna de las dos quería hacer. Aun así, dentro de este episodio hay más referencias de las que cabría esperar. Como ya hemos visto, en los tres casos hay un rapto. Perséfone es arrebatada violentamente del mundo terrenal para bajar al Hades, como queda recogido en el Himno II, que Homero le dedica a Deméter:

Comienzo por cantar a Deméter de hermosa cabellera, la augusta diosa; a ella y a su hija de esbeltos tobillos, a la que raptó Aideoneo (y lo permitió Zeus tonante, cuya voz se oye de lejos), cuando apartada de Deméter la del arma de oro, de hermosos frutos, jugaba con las muchachas de ajustado regazo, hijas de Océano, y recogía flores... (Homero, Poemas homéricos, iI. 63).

A su vez, Eurídice sufre un intento fallido de sustracción por parte de Aristeo:

La cólera de un numen se vuelve contra ti; expías una gran falta: el desdichado Orfeo, con anuencia de los hados, te origina castigos, no tan graves como mereces, y se irrita cruelmente por la pérdida de su esposa. Aquella muchacha, destinada a morir, por cierto, mientras escapaba de ti precipitándose por los márgenes de los ríos, no vio ante sus plantas una horrible serpiente que vigilaba las riberas sobre el alto pajonal... (Virgilio, Geórgicas, Iv. 453-459).

Por último, Ginevra es hechizada y llevada a la Cámara de los Secretos. Sabemos que ha sido secuestrada porque en la escena previa al descendimiento de Harry y Ron en busca de la muchacha, la subdirectora de la escuela comunica a los profesores (Harry Potter y la Cámara..., 1: 54: 08):

-Nuestros peores temores se han cumplido. Una alumna ha sido raptada por el monstruo y llevada a la Cámara. Los alumnos deben regresar a sus casas [...] me temo que éste es el final de Hogwarts.

Pero ¿cómo acaban los destinos de Eurídice y Perséfone? ¿Y el de Ginny? Las dos últimas consiguen volver con sus madres. Afortunadamente, la hermana de Ron es rescatada de Tom Riddle por completo «mientras que el de Perséfone (el rescate) es estacional» (Spencer, 2015: 89). Eurídice, por su parte, queda condenada al Hades, ya que Orfeo habrá sido incapaz de mantener la mirada al frente antes de salir de los dominios del dios griego. Pero las relaciones con Eurídice se extienden también a sus salvadores; y es que tanto Orfeo como Harry consiguen entrar en el mundo subterráneo, aunque el primero consiga devolver a la muchacha a su familia mientras que Eurídice regresaría al Hades.

Hablemos ahora de los referentes utilizados en la puesta en escena y de los elementos iconográficos tomados de las artes plásticas de siglos pasados.

Las relaciones entre el Hades griego y la Cámara de los Secretos de J.K. Rowling son más que evidentes. La asociación aparece tras abrir Harry el pasadizo que lleva hasta ella desde el baño de los prefectos.

Para Homero y Hesíodo, el Hades no era otra cosa que un lugar oscuro y subterráneo que estaba dividido en varias partes, entre ellas el Erebo, el Tártaro o los 

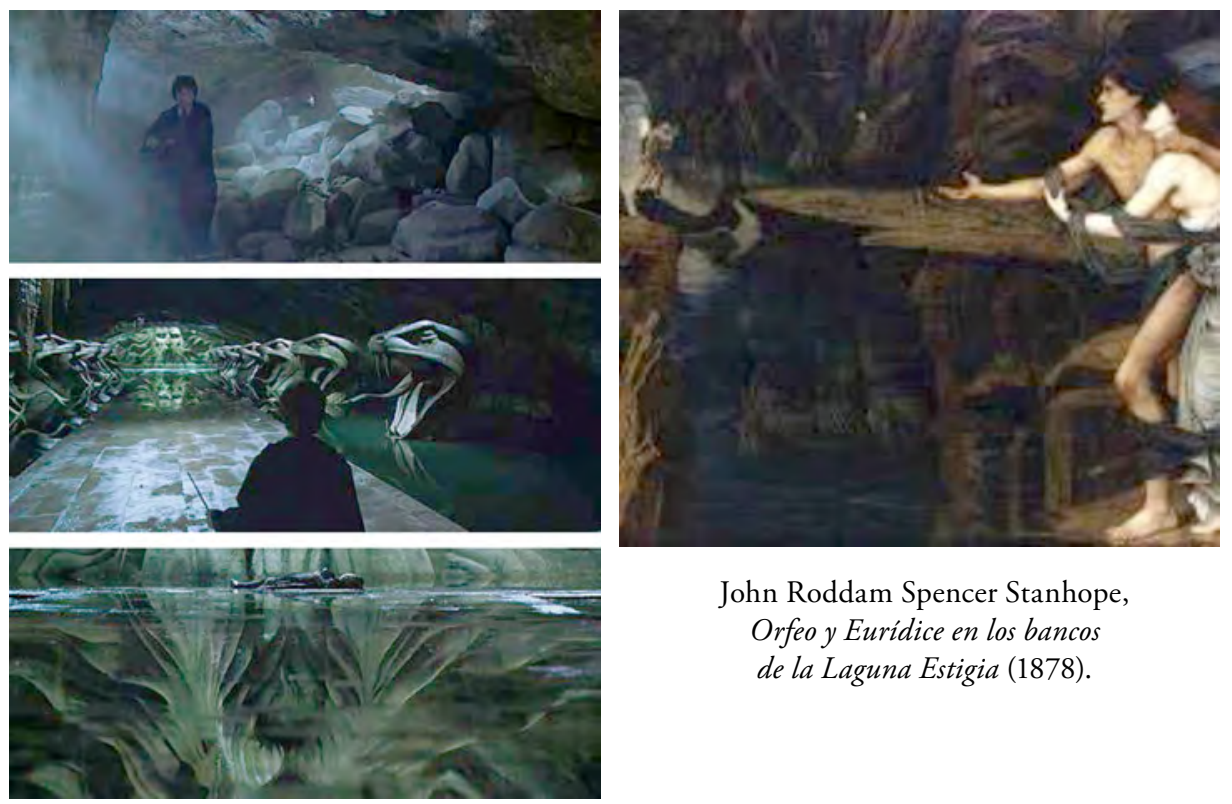

John Roddam Spencer Stanhope, Orfeo y Eurídice en los bancos de la Laguna Estigia (1878).

Fotogramas de Harry Potter y la Cámara de los Secretos (2002).

Campos Elíseos y cuya entrada estaba cerca del mar o de un río. Llama la atención que la escritora británica situase la entrada a la Cámara en el baño de los prefectos de la cuarta planta, a través de una cañería. A diferencia de los griegos, que tenían que cruzar la Laguna Estigia para llegar al Inframundo, Harry tiene un camino que le lleva hasta la misma entrada. No obstante, el agua también está presente en la Cámara, ya que parece que tenemos una especie de laguna en donde se sitúa la plataforma que lleva hasta la colosal estatua de Salazar Slytherin.

Una vez en ésta podemos observar las magnitudes de la misma. El plano general que Columbus nos muestra parece inspirado en la obra de John Roddam Spencer Stanhope Orfeo y Eurídice en los bancos de la Laguna Estigia (1878). En ambas imágenes estamos ante un espacio subterráneo y rocoso. En el plano el punto de fuga se sitúa en la entrada de la morada de la bestia, mientras que en el lienzo se utiliza la entrada al propio Hades llegando a ver la figura de Caronte en su barca. En el cuadro, Orfeo y Eurídice esperan para cruzar la Laguna Estigia, mientras que alrededor del cuerpo de Ginny hay un charco de agua que recuerda a la laguna. Los puntos lumínicos en ambos casos se concentran en los cuerpos de los personajes.

Obviamente estamos abordando el descenso al Hades de J.K. Rowling desde la mitología griega, pero llama la atención que «el viaje» en el que se embarcan para llegar a la puerta de la Cámara de los Secretos y acceder a ella se asemeja en parte al que tenía que hacer el faraón diariamente para seguir vivo en el más allá. En un 

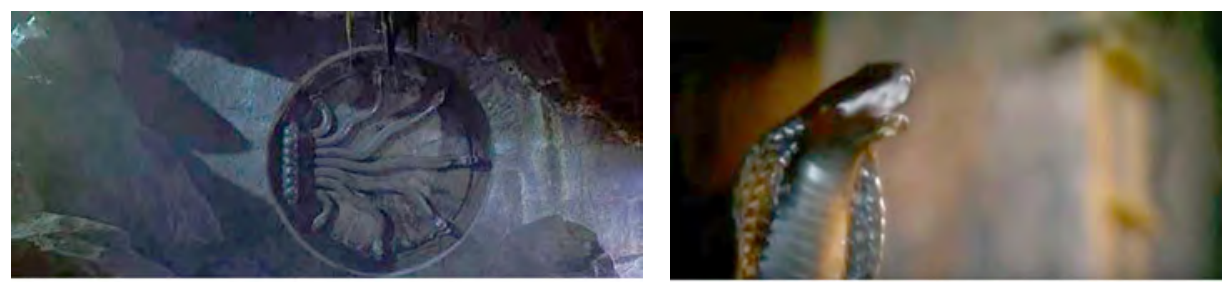

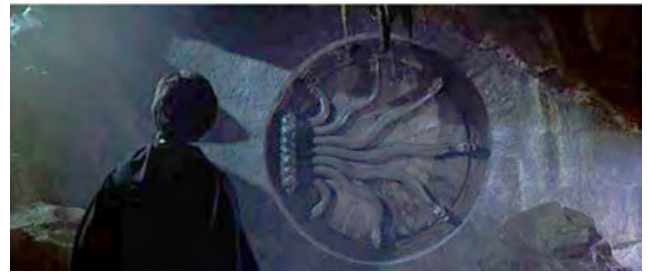

Fotogramas de Harry Potter y la Cámara de los Secretos (2002).

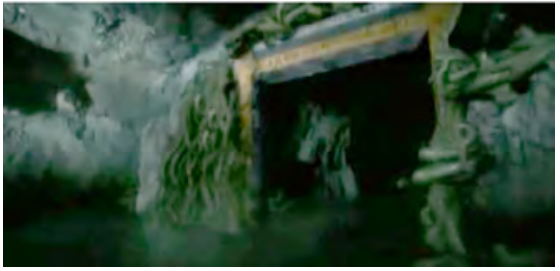

Fotogramas del documental El Inframundo egipcio (2008).

documental emitido por la National Geographic y dirigido por Rob Lyall, Zahi Hawass y la Dra. Salima Ikram reflexionan sobre el tema con las siguientes palabras:

El faraón seguirá una versión del Río Nilo en la otra vida. Esta noche tiene que atravesar doce puertas, una por cada hora de la noche. Cada puerta está guardada por terribles serpientes. El cometido de las serpientes no está que impedir que las atraviesen aquellos que no sean puros o que no tengan el poder mágico suficiente para pasar al siguiente. Como muchos creyentes modernos, los egipcios que buscaban la vida eterna tenían que tener un espíritu puro pero también tener conocimientos de magia. El faraón no puede cruzar las puertas a menos que conozca la palabra secreta de las serpientes que las guardan. [...] cuando pronuncia sus nombres éstas retroceden y puede pasar (El Inframundo egipcio, 4: 55).

Al igual que sucede en el Libro de los Muertos egipcio, Harry llega hasta la entrada de la Cámara de los Secretos, en cuya puerta hay labradas varias serpientes. Para poder acceder a su interior tiene que hablar en pársel, la lengua de los reptiles, $y$, al igual que sucede con el faraón, una a una se van retirando hasta que la puerta se abre ante el joven. Este papel "protector» de las serpientes ya existía desde el Egipto Antiguo; fueron éstos quienes les confirieron ese papel de «guardianes custodios de un tesoro, en este caso de un tesoro inmaterial simbolizado por las aguas: el Conocimiento" (Rodríguez Pérez, 2006: 10). Los griegos por su parte hicieron lo mismo, encarnado en este caso en Pitón, una serpiente engendrada y enviada para custodiar el lugar profético de Delfos. Además, la pelea titánica que establece Harry con el basilisco bien podríamos relacionarla con la lucha que mantiene el faraón contra Apep -Apofis en griego-. Apofis era una divinidad negativa para los egipcios. Su función consistía en interrumpir el recorrido que hacía el faraón en la otra vida con la única finalidad de que éste no alcanzase la vida eterna. Apofis era una serpiente 


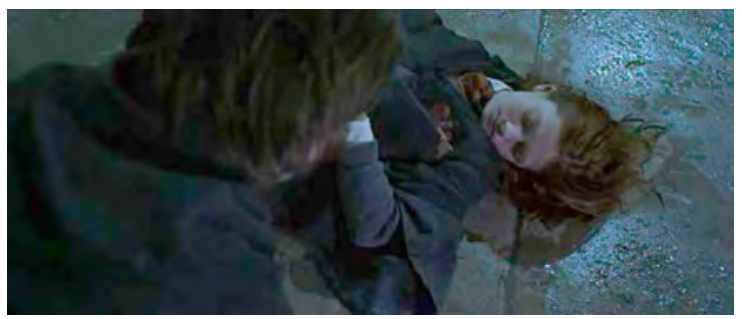

Fotograma de Harry Potter y la Cámara de los Secretos (2002).

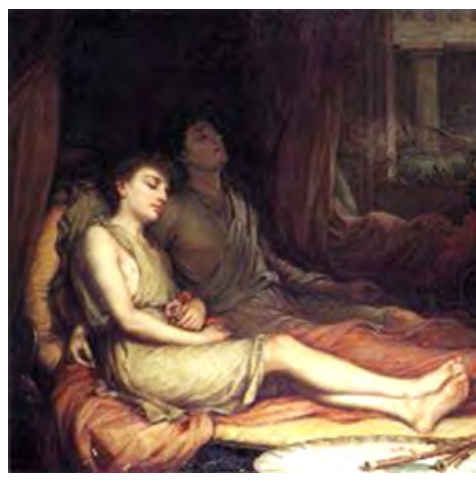

John William Waterhouse, El sueño y su hermanastro la muerte (1874).

poderosa e indestructible. Ésta sólo podía ser contenida al paso del rey egipcio, ya que si se destruía por completo desaparecía el ciclo solar. Algunos arqueólogos coinciden en señalar que se trataba de un reptil que no podía escuchar ni tampoco ver, sólo gritar (Castel, 2001: 28). En ambos casos, tanto en el de Harry como en el del faraón, se trata de un enfrentamiento arduo y exhausto.

Como podemos observar, las semejanzas entre la vińeta del Libro de los Muertos o Libro de la Salida al Día en el original egipcio y la escena del filme son evidentes.

Volviendo al relato, en su momento culminante nos encontramos a Ginny tendida en el suelo al borde de la muerte. El rostro de la joven nos recuerda indudablemente a un cuadro pintado por Waterhouse, El sueño y su hermanastro la muerte. Aunque la postura no sea idéntica, ya que Ginny está acostada y las figuras del cuadro están sentadas en una cama, lo cierto es que el rostro de los tres personajes parecen ser el mismo. No sabemos si Ginny está muriendo o simplemente está soñando o dormida.

Cuando Harry consigue llegar hasta ella, la joven parece estar muerta. Esta imagen parece inspirarse en dos obras de George Federick Watts (fig. 1) y Ary Scheffer (fig. 2). En ambas observamos cómo Eurídice yace muerta tras haber sido mordida por una cobra en su talón; imagen que se repite en el momento en el que Harry se reclina sobre la joven Weasley para ver su estado. La composición es muy parecida en las tres escenas, a pesar de que los cuadros únicamente se centren en el cuerpo de ambos protagonistas. Los dos ocupan el foco central de las obras, bien iluminados y rodeados por sombras y espesa vegetación, dando la sensación de que el espacio es inhóspito y sombrío. Como hemos dicho, la luz queda únicamente reservada para los jóvenes, especialmente para la muchacha. En la película no es diferente. El momento culmen de la escena combina planos cortos de Harry Potter con generales de la Cámara hasta que ambos se encuentran a los pies de la estatua 


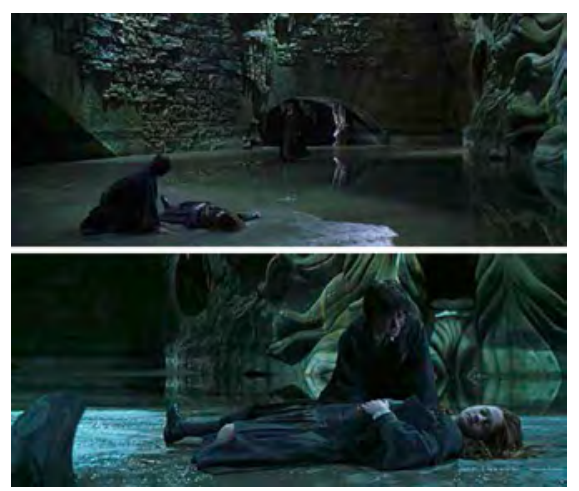

Fotogramas de Harry Potter y la Cámara de los Secretos (2002).

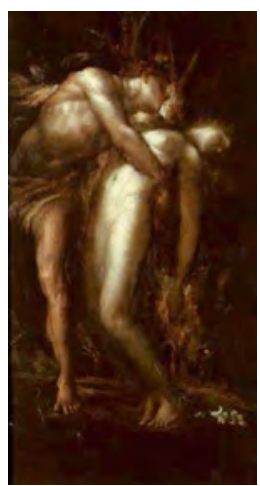

Fig. 1.

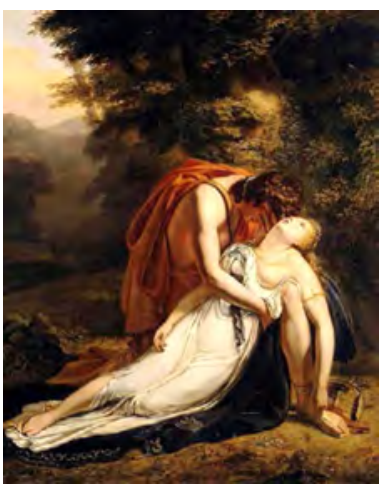

Fig. 2.

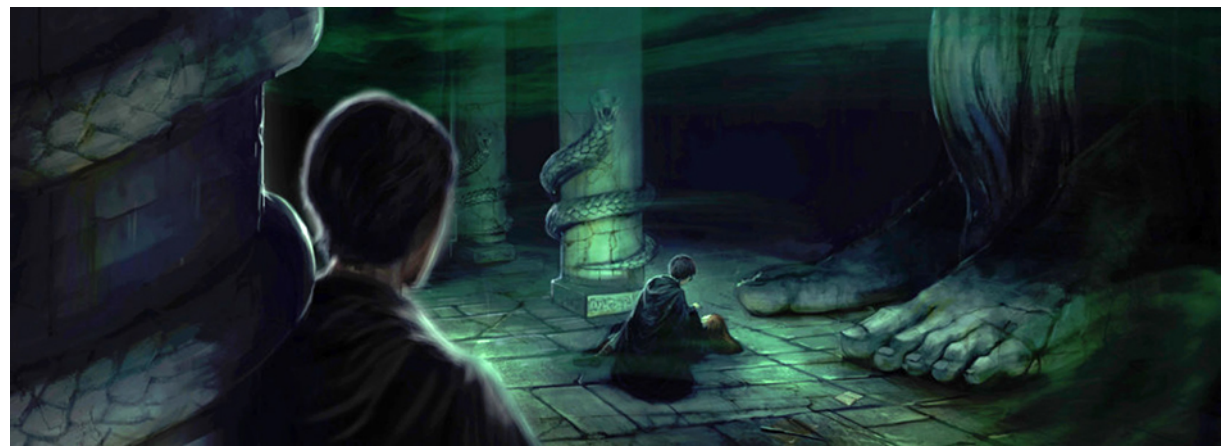

Ilustración de pottermore. Harry encuentra a Ginny en la Cámara de los Secretos.

colosal de Salazar Slytherin, en un medio lúgubre, oscuro y frío en el que destaca la piel marmórea de Ginny, como bien resalta la fotografía de Roger Pratt.

En lo que respecta a la salida de las tres jóvenes, es cierto que ésta no se produce de la misma manera. Perséfone se convierte en la reina del Inframundo mientras que Eurídice, lamentablemente, se pierde para siempre en él. En el caso del filme, Fawkes agarra al profesor Lockhart y de éste van Ron, Harry y Ginny. Aparentemente no hay similitudes entre la película y la escena mitológica, pero sí con una de las representaciones plásticas de la salida de Orfeo y Eurídice del Hades. Si nos fijamos en Orfeo y Eurídice de Anselm Feuerbach, la manera en la que él la rodea con su brazo es la misma con la que Harry sostiene a Ginny mientras regresan al castillo.

Deberíamos indicar que los referentes iconográficos tienen una obvia base pictórica, como hemos podido ir viendo a lo largo del trabajo, pero bien es cierto 


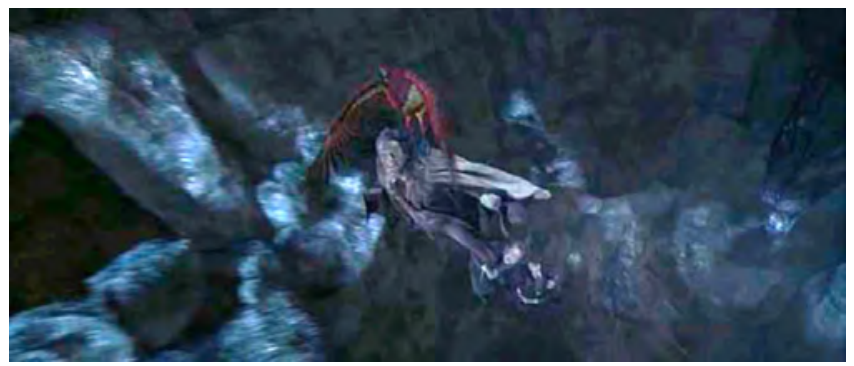

Fotograma de Harry Potter y la Cámara de los Secretos (2002).

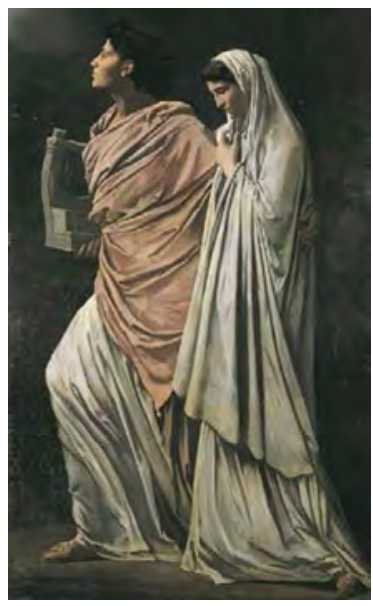

Anselm Feuerbach, Orfeo y Eurídice (1869).

que el equipo artístico de las películas se cuida especialmente de mostrar cuáles fueron aquellas obras en concreto que les sirvieron como inspiración para la creación de las mismas; por tanto, la selección que hemos hecho deriva de nuestra propia investigación, cotejando artes plásticas y cine.

Volviendo al tema que nos ocupa, en el caso de la serpiente de la historia, convertida en un basilisco, que para griegos y hebreos era un áspid venenoso de pequeño tamaño, aquí resulta estar sobredimensionado.

Varios son los autores que la mencionan. En la Antigüedad, por ejemplo, Plinio el Viejo, en su Historia Natural, habla de ella como un híbrido, afirmando que había nacido de un huevo de gallina empollado por un sapo. Muchos siglos después, William Shakespeare, en su obra Ricardo III, narra cómo el hermano de éste había encontrado la muerte tras mirar a este reptil, lo que demuestra que las características lesivas y malignas del animal/monstruo se habían mantenido a lo largo del tiempo sin apenas cambios sustanciales.

La representación de este animal durante la Antigüedad y la Edad Media no es otra cosa que el resultado de la combinación de una serpiente y un pájaro, con el cuerpo del primero y la cabeza y las patas del segundo (Waltz, 2016: 48). No obstante, Rowling decide decantarse por una grande y colosal, que bien podría recordarnos a una anaconda. En la escena en la que Hermione Granger es atacada por éste, deja una pista a sus amigos sobre cómo era el monstruo que habitaba la cámara. Se trata de un trozo de papel que enunciaba lo siguiente:

De las muchas bestias pavorosas y monstruosas terribles que vagan por nuestra tierra, no hay ninguna más sorprendente ni más letal que el basilisco, conocido como el rey de las serpientes. Esta serpiente, que puede alcanzar un tamańo gigantesco y 


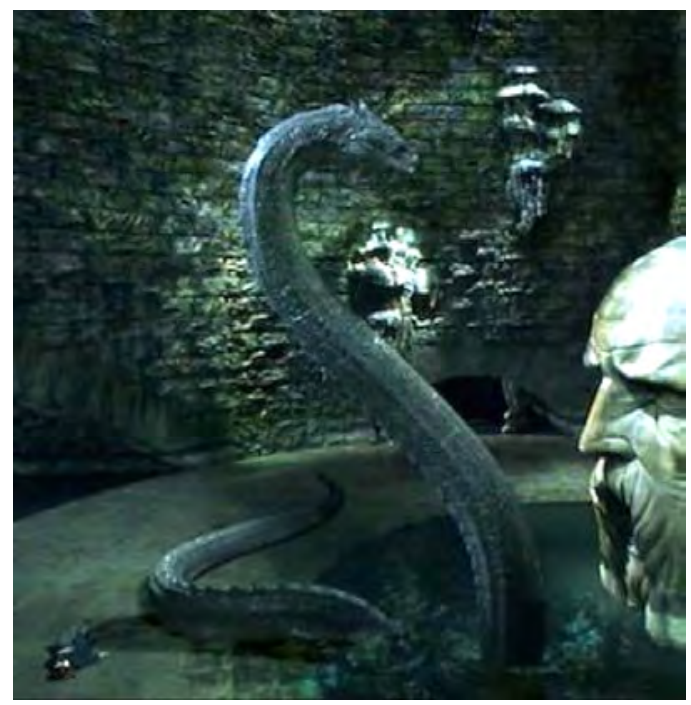

Fotograma de Harry Potter y la Cámara de los Secretos (2002).

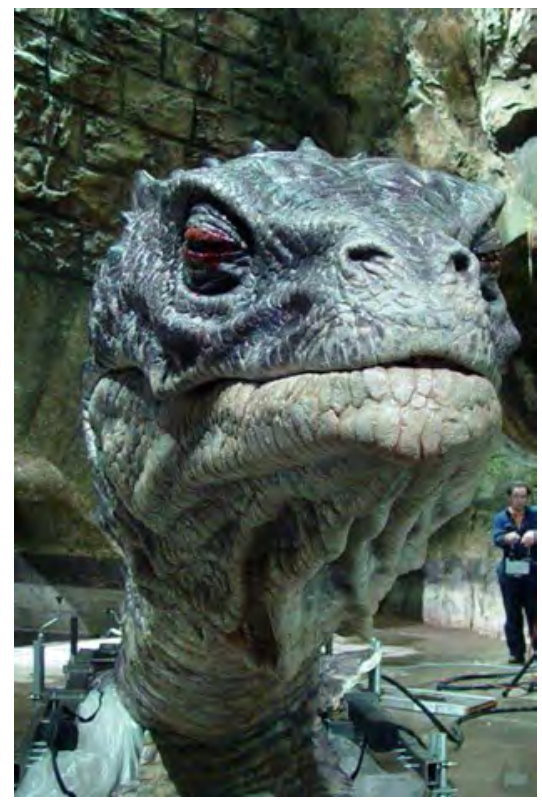

Detalle de la cabeza del basilisco en los estudios de Leavesden (Londres).

cuya vida dura varios siglos, nace de un huevo de gallina empollado por un sapo. Sus métodos de matar son de lo más extraordinario, pues además de sus colmillos mortalmente venenosos, el basilisco mata con la mirada, y todos cuanto fijaren su vista en el brillo de sus ojos han de sufrir instantánea muerte. Las arañas huyen del basilisco, pues es éste su mortal enemigo, y el basilisco huye sólo del canto del gallo, que para él es mortal (Rowling, 1998: 245).

Su existencia no sólo se remonta a la civilización griega, como ya hemos dicho anteriormente. Conocemos la existencia de un reptil colosal en el Libro del Amduat o "Libro de lo que hay en el otro mundo». Se trataba de una composición religiosa que describía el viaje nocturno -dividido en doce horas-del faraón por el más allá. Esta serpiente aguardaba en la séptima hora a éste. Como ya hemos apuntado anteriormente, su función no era otra que malograr el viaje del monarca y que éste no alcanzase la vida eterna. En la traducción realizada por López y Thode podemos darnos cuenta de esa semejanza entre los áspides. Ambos viven bajo tierra, en cuevas subterráneas. Son la representación del mal. Ambas están ciegas -la de Rowling tras su pelea con Fawkes- y son capaces de petrificar con tan sólo una mirada a sus víctimas.

El misterioso camino del Oeste por el que el Gran dios pasa en su sagrada barca. Él pasa por este camino que está sin agua, sin ser remolcado, avanza por las invo- 
caciones mágicas de Isis, y por las invocaciones mágicas del Más Antiguo así como también por la excelencia de las invocaciones de este mismo dios. Haciendo pedazos a Apofis en la Duat encerrado por esta cueva y al mismo tiempo en el cielo (?). Esto se ha hecho exactamente como está representado en el Norte de la Cámara Oculta de la Duat. Un espíritu en el cielo, en la tierra y sobre la tierra que sepa esto llegará a ser uno de los espíritus (?) que están ante Ra (López y Thode, 2002).

Es evidente que las características que tiene el áspid de Rowling son muy similares a la de la civilización del Nilo. En una descripción más detallada de la divinidad egipcia leemos lo siguiente:

... La mayor amenaza en su periplo nocturno la constituía la serpiente Aapep (la Apofis griega), que con su mirada podría petrificar al séquito de la barca del astro y con sus fauces podría absorber gran cantidad de agua impidiendo en ambos casos que la embarcación continuara navegando (Díaz-Iglesias Llanos, 2012: 89).

Por su parte, Rowling, en el bestiario ${ }^{2}$ que utilizan los alumnos para estudiar a las criaturas fantásticas que habitan su mundo, lo hace así:

(también conocido como «rey de las serpientes») [...]. El primer basilisco del que hay constancia fue criado por Herpo el Loco, un mago tenebroso de Grecia que hablaba pársel. Después de muchos experimentos, Herpo descubrió que de un huevo de gallina incubado por un sapo salía una serpiente gigantesca dotada de poderes extraordinariamente peligrosos. El basilisco es una serpiente verde brillante que puede alcanzar más de quince metros de largo. El macho luce una pluma escarlata sobre la cabeza. Tiene colmillos excepcionalmente venenosos, pero su arma más mortífera es la mirada. Cualquiera que mire directamente a sus grandes ojos amarillos morirá al instante (Rowling, 2010: 4-5).

Como podemos observar, son numerosas las semejanzas entre las bestias de los egipcios, de los griegos y de la escritora británica. Destaca de manera sobresaliente el tamaño del reptil y su capacidad para matar, en los dos textos, con sólo su mirada. Pero las similitudes no acaban con la descripción del monstruo, pues, por un lado, nos llama la atención la manera en que los dioses o héroes se enfrentan al mismo. Aunque en el caso de los egipcios Apofis no termine de morir nunca, lo cierto es que la única manera de mantenerlo a raya mientras el faraón consigue llegar al juicio de las almas es clavándole lanzas y espadas, como vemos en un fresco que describe la tumba de Sennedjem en el Deir el Medina. Por otro lado, la muerte de Pitón a manos de Apolo se produce igualmente tras asaetearla con sus flechas. Lo mismo ocurre en el filme, pues tras una ardua y fatigada lucha con el monstruo, Harry consigue clavarle -como podemos observar en el fotograma- la espada de Godric Gryffindor y darle muerte.

\footnotetext{
${ }^{2}$ Libro redactado por Newt Scamander, Animales Fantásticos y dónde encontrarlos.
} 


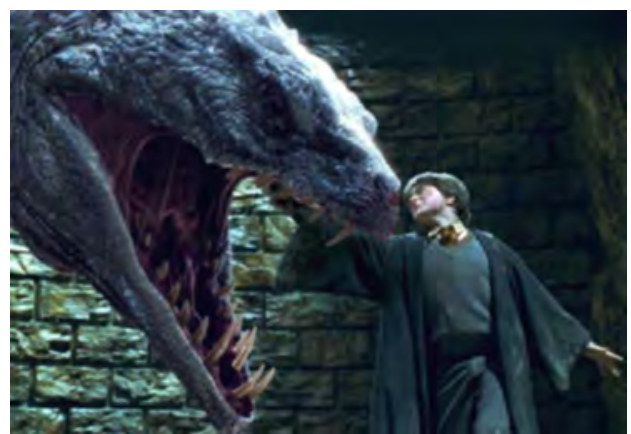

Fotograma de Harry Potter y la Cámara de los Secretos (2002).

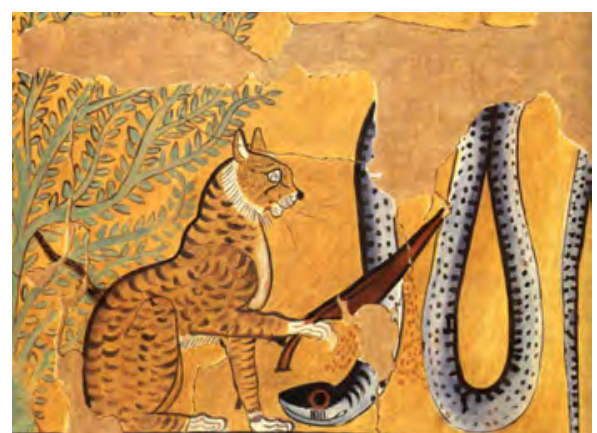

Pintura egipcia sobre la muerte de Apofis.

Para concluir debemos indicar que Ginny no sufre un ataque propiamente, pero sí es el instrumento de Tom Riddle para atemorizar a estudiantes y profesores de Hogwarts tras los ataques perpetrados por la bestia.

Por tanto, en este apartado apreciamos con claridad cómo la selección creativa del equipo de Columbus está inspirada tanto en las fuentes literarias clásicas como en obras de artistas decimonónicos, además de las evidentes semejanzas con los relatos egipcios sobre Apep.

\section{LA CÁMARA DE LOS SECRETOS COMO PUNTO DE INFLEXIÓN EN GINNY WEASLEY}

Al igual que sucede con Perséfone y Eurídice, antes del rapto, Ginevra se nos presenta como una muchacha vulnerable, tranquila, una chica de buena conducta, inconsciente de su propia fortaleza o de sus poderes como «bruja». Obviamente quiere agradar, sobre todo a Harry, de quien está enamorada desde que se conocieron.

Releyendo a Shinoda Bolen ${ }^{3}$, quien ha dedicado sendos estudios a la figura de la mujer y del personaje de Perséfone, entendemos que tras el descenso de ésta al Hades y su conversión en reina de éste, se transforma en una mujer madura y activa, convirtiéndose en un personaje importante en episodios como el de Orfeo y Eurídice. Estas mismas palabras referentes al cambio de personalidad que sufre la hija de

3 Shinoda Bolen es doctora en medicina, además de psiquiatra y analista. Ha escrito diversos libros y dado varias conferencias relativas a la espiritualidad, el feminismo, la psicología analítica y la medicina, entre ellas "Goddesses in older women: archetypes in women over fifty» (2001) o «Goddesses in every woman: powerful archetypes in women's lives» (2004). 
Deméter podemos extrapolarlas a la joven de los Weasleys, quien tras este episodio traumático comienza su transformación. Asistimos a un cambio físico pero sobre todo psicológico. Si antes hablábamos de una niña que estaba supeditada, al igual que Perséfone, a las exigencias de su madre, obedeciendo, con una actitud pasiva en las primeras novelas, cambiará, y de una manera progresiva, a partir de este episodio. Ginevra empieza a desarrollar una personalidad fuerte sin dejar esa dulzura y timidez que la caracterizaban y adquiere un papel activo cuando decide formar parte, no sólo de la Orden del Fénix ${ }^{4}$, sino también del Ejército de Dumbledore; ; ejército que será decisivo en la batalla final contra lord Voldemort y todos sus motífagos ${ }^{6}$.

Las historias de Perséfone y Ginny -no la de Eurídice, pues ésta queda en el Hades- son un claro ejemplo de empoderamiento femenino, pues ambas cambian su carácter y su psicología para, tras asumir su nueva situación, convertirse en protagonistas de su propio destino. A partir de ese momento su participación en los diferentes relatos en los que aparecen será notablemente diferente a la que habían tenido previamente -antes de su cambio-.

Este «renacimiento» en lo personal y en lo psicológico queda subrayado por la utilización de Fawkes en la escena final de la Cámara de los Secretos puesto que el simbolismo del ave fénix alude directamente a ese nuevo renacer tras la posesión y el rapto de la joven.

La aparición del Fawkes en esta escena no es gratuita, y no sólo porque proporcione a Harry el arma con la que matará al basilisco o porque consiga cegarle para ayudar al joven héroe, sino porque actuará como una pieza clave en el desenlace de la historia. A este animal mitológico se le conoce desde tiempos del Antiguo Egipto, en donde se le relacionaba con la purificación y la inmortalidad. Los griegos, por su parte, también sabían de su existencia:

Otra ave sagrada hay allí que sólo he visto en pintura, cuyo nombre es el de fénix. Raras son, en efecto, las veces que se deja ver, y tan de tarde en tarde, que según los de Heliópolis sólo viene al Egipto cada quinientos años a saber cuándo fallece su padre. Si en su tamańo y conformación es tal como la describen, su mote y figura son muy parecidas a las del águila, y sus plumas en parte doradas, en parte de color de carmesí. Tales son los prodigios que de ella nos cuentan, que aunque para mi poco dignos de fe, no omitiré el referirlos (Heródoto, Historia, II, LXXIII).

${ }^{4}$ La Orden del Fénix es una organización secreta fundada por Albus Dumbledore para luchar contra lord Voldemort y sus mortífagos.

${ }^{5}$ El Ejército de Dumbledore fue una organización secreta creada por Hermione Granger y Ron Weasley. Su finalidad era que los estudiantes de Hogwarts aprendiesen Defensa contra las Artes Oscuras de una manera apropiada a través de los conocimientos de Harry Potter en respuesta al Régimen «Inquisitorial» que impuso Dolores Umbridge tras su llegada al colegio como profesora de dicha materia.

${ }^{6}$ Mortífago: es un seguidor incondicional de lord Voldemort. Muchos afirman ser amigos del Señor Tenebroso aunque más bien son sus lacayos. Ningún muggle o «sangre sucia» puede formar parte de este grupo. 

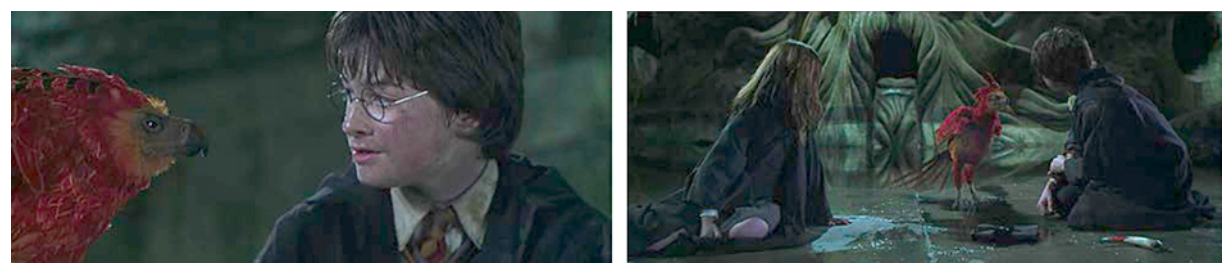

Fotogramas de Harry Potter y la Cámara de los Secretos (2002).

La llegada del cristianismo no supuso la desaparición de éste, sino más bien todo lo contrario. El fénix se exponía al sol, ardía y renacía nuevamente; convirtiéndose así en la mejor representación del triunfo de la vida sobre la muerte. Los cristianos decían de él «que fue la única bestia que se negó a probar la fruta del paraíso, cosa que fue recompensada por Dios con el poder de la luz, el fuego y la inmortalidad» (Manu González, 2018: 186).

Por tanto, su uso en el relato de Rowling adquiere una significación simbólica, aludiendo al nuevo estatus de la protagonista del episodio que estamos tratando.

\section{CONCLUSIONES}

Como bien sabemos, la obra de J.K. Rowling está plagada de incontables referencias al mundo clásico y a otras mitologías europeas.

A pesar de ello la autora no copia relatos y los traslada a la novela -y más tarde sus guionistas a la gran pantalla-, sino que toma "prestada» una misma estructura narrativa que tratará de adaptar. En este caso usa dos episodios míticos, los de Perséfone y Eurídice, para nutrir y enriquecer a un personaje que cambiará sustancialmente después de su particular descenso al Hades: Ginny Weasley.

Aunque el equipo encargado en el filme del diseño de arte no aporte información de los referentes pictóricos que se emplearon como modelos creativos para la puesta en escena de esta secuencia, lo cierto es que parecen haber utilizado algunas obras de la pintura finisecular decimonónica. Cada imagen, cada plano, nos recuerda a obras de Dante Gabriel Rosetti, Edward Burne-Jones, John William Waterhouse o Gustave Moreau. Asimismo, la relación entre la pintura y la arquitectura es destacable, ya que la historia transcurre en espacios de inspiración neogótica, ecléctica historicista o bien de estilo victoriano, que marcaron las edificaciones más significativas de dicho siglo en Inglaterra y parte de Europa. De hecho y a pesar de que partir de la tercera película -dirigida por Alfonso Cuarón- ya se rueda en los estudios de Leavesden (Londres), las anteriores se emplazaron en lugares que recorrían toda la geografía británica: por ejemplo, el callejón Diagon está inspirado en la calle Victoria de Edimburgo, el patio de Hogwarts en el claustro de la catedral de Durham y los terrenos del castillo anterior en el valle de Glencoe, en Escocia, entre otros. 
Pero las concomitancias no sólo están en el plano artístico. En un momento en donde se está reivindicando el papel de la mujer en todas las facetas de la vida, asistimos al empoderamiento como mujer de Ginevra Weasley. Antes de ser hechizada su psicología se acercaba más a la de Eurídice, una niña inocente a la sombra de sus hermanos. Obviamente, tras enfrentarse con el mal y gracias a la ayuda de Harry, sufrirá una serie de cambios profundos, en su psiquis, en su comportamiento e incluso en su físico, dejando atrás ese papel pasivo que había mantenido hasta ese momento para, al igual que Perséfone, adquirir otro más activo en la historia, convirtiéndose en uno de los personajes más apasionantes y con más matices que la autora nos presenta en su saga.

Finalmente, las relaciones con la mitología egipcia son llamativas, ya que hasta la fecha no habíamos encontrado referencias claras a la misma. No sabemos si J.K. Rowling había profundizado sobre el panteón egipcio y si se valió de ello para articular su historia, pero lo que tenemos claro es que detrás de esta saga, aparentemente infantil y juvenil, hay un imaginario que lo que hace es enriquecer, aún más, la historia del «niño que sobrevivió». 


\section{BIBLIOGRAFÍA}

Botas Ramos, P. (2001): «El espacio fantástico en el cine y la literatura: una aproximación comparativa", Lecturas, imágenes: revista de poética del cine, 1, 149-160.

Castel, E. (2001): Gran Diccionario de Mitología Egipcia, Madrid, Aldebarán.

Díaz-Iglesias Llanos, L. (2012): «El fin del mundo en textos funerarios y mágicos egipcios y la destrucción de la humanidad en Heracleópolis Magna», Revista ARYS, 10, 87-112.

Dover, C. (2017): «From Marie de France to J.K. Rowling: The Weasel», en Nelson-Campbell, D. \& Cholakian, R. (eds.), The Legacy of Courtly Literature. From Medieval to Contemporary Culture, (91-113), Switzerland, Palgrave McMillan.

Elvira Barba, M.A. (2008), Arte y mito. Manual de iconografía clásica, Madrid, Sílex Ediciones.

Groves, B. (2017): Literary allusion in Harry Potter, New York, Routledge.

Heródoto: Historia.

Homero: Poemas homéricos.

López, F. y Thode, R.: El Libro del Amduat. Consultado el 07 de octubre de 2018, de http://egiptologia.org/?page_id=1014.

Pérez, H.J. (2013): Cine y mitología. De las religiones a los argumentos universales, Suiza, Peter Lang A.G., International Academic Publichers.

Popa-Liseanu, D. (2012): "El mito de Proserpina en la vida y obra de la Princesa Bibesco», en Almela, M., Guzmán, H., Leguen, B. y Sanfilippo, M. (eds.), Tejiendo el mito (200214), Madrid, Universidad Nacional de Educación a Distancia.

Rodríguez PÉrez (2006): «El combate contra la serpiente: el triunfo de la tierra velado bajo la aparente muerte del ofidio». Revista de Arte, 5, 5-14.

Rowling, J.K. (1998): Harry Potter and the Chamber of Secrets, London, Bloomsbury.

Rowling, J.K. (2010): Animales Fantásticos y dónde encontrarlos, Barcelona, Salamandra.

Serrano Lozano, D. (2012): «Cine y Antigüedad: pasado y presente en la pequeña y gran pantalla", Revista Historia Autónoma. Revista Multidisciplinar de la Asociación Historia Autónoma, 1, 37-52.

Spencer, R.A. (2015): Harry Potter and the Classical World. Greek and Roman allusions in J.K. Rowling's Modern Epic, North Carolina, McFarland \& Company.

VIRGILIO: Geórgicas. 